\title{
El libro de devoción como modelado y modelador de la conducta social: el «Luz a los vivos" de Palafox (1668)
}

\section{LEÓN CARLOS ÁLVAREZ SANTALÓ Universidad de Sevilla}

\begin{abstract}
"Es menester que sepamos y nos quitemos de la cabeça los ricos, y los pobres y los grandes y los chicos, los poderosos $\gamma$ los desvalidos, que no podemos hazer lo que queremos, sino lo que es razon). JUAN DE PALAFOX
\end{abstract}

En distintas ocasiones me he referido al papel del libro de devoción en la organización de la vida de la sociedad barroca (1), como paradigma, sin duda, pero no en menor medida como un método de transferencia doctrinal. Este último aspecto, buscado conscientemente, no se interesa tanto por los conjuntos dogmáticos cuanto por una "doctrina de conducta"; una batería de normas y mensajes que van conformando un estilo de vida. Todo ello de forma sesgada, en el sentido de irse introduciendo al abrigo de las "historias» de santos, apariciones, ánimas del purgatorio y el variopinto mundo de los "exempla" y los inagotables florilegios de apólogos morales. En este sentido podemos utilizar como prueba (seguramente no excepcional) una de las obras de mayor difusión en los ss. XVII y XVIII (a tenor de su insistente presencia en los inventarios notariales de bibliotecas), el "Luz a los vivos y escarmiento en los muertos" de D. Juan de Palafox y Mendoza, obispo de Puebla y de Burgo de Osma, editado en 1668, (en folio). Es evidente

(1) L.C. ALVAREZ SANTALÓ, "Librerías y bibliotecas en la Sevilla del s. XVIII", en Actas del II Coloquio de Metodología Histórica aplicada. Santiago 1984, vol. II. pp. 165-85. "Adoctrinamiento y devoción en las bibliotecas sevillanas del s. XVIII", en Actas del I Coloquio sobre Religiosidad popular Fundación Antonio Machado (1987), Barcelona 1989. 
que un libro tan extenso no se deja analizar en unas pocas páginas, pero me interesa más esclarecer el modelo que la exhaustividad.

\section{UN METODO CONSCIENTE}

EL «Luz a los vivos...» constituye un ejemplo «sui generis» del tipo de libro de estados. Viejo modelo retórico, es conocido su éxito y, en consecuencia, su enorme reiteración en el área del libro devocional como nos recuerda Caro Baroja (2). Se trata, en definitiva, de organizar los mensajes ordenándolos por grupos peculiares de receptores; cada lector tiene entonces una parte del libro específicamente dedicada a él-(en cuanto miembro de un estamento e incluso de sus diferentes subgrupos de actividad, cuando es pertinente), además de poder "beneficiarse" de los aspectos generales que puede extraer de los mensajes dirigidos a los otros grupos. Con todo, la eficacia de este modelo no se agota en adecuar los mensajes (y con ellos los tics de conducta) a las peculiaridades de vida y status de cada lector. Al mismo tiempo se le "recuerda" el orden y el concierto del conjunto social exponiendo las cargas, deberes y responsabilidades de los otros grupos. El resultado es que un grupo social cualquiera aprende lo que debe y no debe hacer, pero también lo que los demás deben y lo que no pueden realizar. Así, el esquema contiene ya, inicialmente, un elemento importante de gratificación sicológica: una especie de igualitarismo que le sugiere que no es él, únicamente, el que sufre obligaciones y a quien se le exige una conducta de renuncia o de acción. Cada grupo y subgrupo social quedan equiparados y «compensados" porque, evidentemente, los mensajes dejan bien claro que a cada grado de supuesta superioridad social, acompaña uno equivalente de gravedad al exigírsele responsabilidades proporcionales.

Evidentemente los autores no manifiestan su intención con tanta nitidez, pero tampoco ocultan, en modo alguno, el atractivo didáctico del método. Oigamos, por ejemplo, a otro de los autores más notorios y

(2) CARO BAROJA, J., Las formas complejas de la vida Religiosa; Religión, sociedad y carácter en la España de los ss. XVI y XVII, Madrid 1978, todo el capítulo XIII especialmente los epígrafes 6 (Visión ascética "predicable» de los «Estados») y 5 «Los «estados" y el deber) pp. 291-324 para el capítulo y 308-314 para los epígrafes. No hay que recordar, porque él lo hace, el precedente directo que supone el «Diálogo de Mercurio y Caron» de Alfonso de Valdés y sus modelos anteriores. Por la adecuación absoluta con nuestro libro merecen citarse las líneas en las que nos recuerda que en la obra de Valdés: «Desfilan aquí también las «ánimas", como "estados» que descubren sus faltas y muestran también, a veces, prudentemente, sus posibilidades de perfección», p. 305. 
leídos de la literatura devocional barroco-tardía, José Boneta y Laplana; en una de sus obras más divulgadas, los "Gritos del purgatorio y medios para acallarlos» (3), en la introducción, se refiere a otro libro, en proyecto, (que publicó después, en efecto) y que ofrece al lector con la siguiente, nada oscura, declaración de intenciones: «...ofrecerte otro libro del mismo tamaño cuyo título es "Gritos del Infierno para despertar al mundo". Su idea será introducir a un condenado en cada "estado», haciendo una plática a los de su estado; como un juez condenado a los jueces, un mercader condenado a los mercaderes; un señor condenado a los señores; un eclesiástico... a los eclesiásticos; un labrador... a los labradores y así de los demás estados. La materia de estas pláticas ha de ser expresar lo que padecen y las culpas porque lo padecen (que han de ser las municipales (sic) y propias de cada estado)". Como puede comprobarse no quedan muchas dudas sobre la consciente utilización del modelo y su privilegiado carácter didáctico. Espero, sin embargo, que no haya pasado desapercibida la utilidad funcional (esta vez no expresa) contenida en el estímulo a la curiosidad (intencional, hasta cierto punto "morbosa" y en todo caso "consoladora») por conocer los "pecados" de los otros sectores y status sociales, con la posibilidad, evidente, de compararlos con los propios y hallar, tal vez, una "tabla" de gravedades en la que resulte beneficiada la opinión e imagen que cada lector hace sobre sus propias culpas-vida. Los "Gritos del purgatorio", de Boneta, ya constituyen un ejemplo de este organigrama, si bien atendiendo a un esquema muy general y básico de la sociedad: gritos de las "almas» (del purgatorio) a sus parientes (de las madres a los hijos, de los padres a los hijos, de las mujeres a sus maridos y viceversa); a sus amigos; a sus enemigos; a todos los cristianos y al Rey (como se aprecia, el sistema permite escarceos de "moral política" nada despreciables). Después de este nivel general, Boneta sólo puntualiza dos estamentos, en bloque: los «señores y personas delicadas" y el clero (sacerdotes y religiosos).

Volviendo a nuestro Palafox, hay que señalar que el «Luz a los" vivos" corresponde al género "de estados», pero con peculiaridades que lo hacen muy superior a sus "colegas» y específicamente al de Boneta.

(3) 'BONETA Y LAPLANA, J., Gritos del purgatorio y medios para acallarlos; Barcelona, sin año de edición; Imprenta de M. ${ }^{*}$ Angela Martí, viuda. En realidad la literatura que podía utilizarse como modelo era ya abundante a mediados del XVII, basta citar la "Breve Instrucción..." de Bartolomé Medina (Salamanca 1579) o la "Agonía del tránsito de la muerte" de Alejo Venegas, de cuya difusión en las bibliotecas sevillanas del s. XVIII di cuenta en otro lugar. 
La primera es que el libro de Palafox no está escrito como un libro construido. Podría decirse que pertenece al género, muy literario por cierto, de utilizar un supuesto (o real) conjunto documental anterior al autor y de distinta mano. En nuestro caso, los «cuadernos» donde una religiosa da cuenta "apretada de la obediencia» de una larguísima serie de apariciones de almas de purgatorio. Palafox ha numerado cada una de estas "relaciones" que transcribe, sin más, en letra cursiva, de una en una (o agrupando algunas) acompañándolas de largos comentarios en los que vierte los mensajes que queremos considerar. El conjunto queda así estructurado como un bosque de doctrina-paradigma, en torno a cada una de las relaciones de la monja, sin más orden. A efectos de funcionalidad, el lector queda, de entrada, atrapado por la columna vertebral de las apariciones y recibirá las propuestas morales de una forma indirecta, muy distinta (y sicológicamente mucho más eficaz) de aquella redacción intelectualizada del libro puramente doctrinal escrito como un ejercicio de sabiduría. Que las anotaciones de la religiosa sean reales o un simple recurso estilístico de Palafox, resulta inoperante a los efectos de eficacia sicológico-didáctica a los que nos referimos; pero la abusiva reiteración, la cortedad y simplicidad del abanico de "estados" representados, el desorden absoluto y la falta de «representantes» más adecuados para un organigrama "brillante" de la vida social, me sugieren la casi seguridad de que los papeles monjiles existieron (cosa por otra parte tan común en la época que lo excepcional sería lo contrario) (4) y que el obispo los utilizó como un "texto-pretexto" para su postura pastoral.

(4) SÁNCHEZ LORA, J.L., Mujeres, Conventos y formas de la Religiosidad barroca, Madrid, 1988. Vid. especialmente los capítulos V, VII y VIII, pp. 207-256; 309-359 y 372-403. Dice el autor: «Existió la revelandera sincera, convencida de la sobrenaturalidad divina de sus acciones... existió la enajenada que dio en querer ser santa... la rutinaria prosa de las causas inquisitoriales encubre con frecuencia la dramática experiencia del triste vivir de mujeres irreversiblemente derrotadas en su aventura personal» (p. 350). Un caso específico muy similar al de nuestra monja vidente es el de Manuela María de Jesús (en JESÚS IMIRIZALDU, Monjas y Beatas embaucadoras, Madrid 1978, pp. 71-81): "Tuvo principio su perdición de haver dicho a ciertas personas havia tenido un sueño en que havia visto almas del purgatorio..." "... pidió al susodicho la comprasse un estuche muy bueno, unas cintas encarnadas y medias y enseñándoselas a las ánimas del purgatorio las decía si las querían...» (pp. 71 y 75). Pero en realidad cualquier visionaria echaba mano de las ánimas a las primeras de cambio; en el mismo libro de IMIRIZALDU, otra de ellas, Magdalena de la Cruz es condenada, entre otras acusaciones, por: «... dixo que era el alma de un fulano que entonces muriera y que estaba en peligro de se salvar y que venía a pedir misericordia... y así decía de otras ánimas que estaban en el purgatorio y otras en el cielo y otras en el infierno"; (p. 58) "Yten dixo más, que engañaba a las gentes 
La segunda es la eficacia de los mensajes percibidos no como producto de la ciencia teológica, sino como la realidad viva de la boca de personas reales (la posibilidad de que un católico del XVII no considere reales a las almas del purgatorio es, prácticamente, despreciable) descritas familiarmente (aunque no se dan nombres, sí se refiere a parentescos, localizaciones, etc, ...). Los comentarios del obispo no destruyen esta perspectiva, sino que la refuerzan, desde el momento en que semejante autoridad presta su aceptación y en ella funda la totalidad de sus mensajes. Por si hubiera alguna duda, Palafox establece en su primer comentario: «... esta religiosa hizo la relación mandada de su Prelada... o de su confesor: y esto afiança mucho el crédito de estas apariciones por lo que Dios alumbra siempre con la obediencia..." (5). Repetidamente, a lo largo de los comentarios insistirá en el crédito que estas apariciones le merecen apoyándose en este u otros "argumentos» como cuando afirma: "Uno de los motivos porque he formado concepto de que son verosímiles estas apariciones es por la igualdad con que aparece que en ellas se purgan cosas y personas... porque me parece muy propio del juicio igualíssimo de Dios» (6). Curiosamente y a este respecto, Boneta, a finales del siglo, no se muestra tan benévolo con las apariciones, de modo que destruye, desde el prólogo mismo, el efecto sicológico de realidad, centrándose exclusivamente en el recurso didáctico de unos gritos metafóricos: «... que no se crean ligeramente las apariciones que suelen correr en este siglo... éste suele ser ardid del demonio... por esto no se ha de dar crédito ni oido a semejantes cosas: ni aunque sea quien las dice Persona santa" (el subrayado es mío) en una transparente alusión a Palafox. En cualquier caso y prescindiendo del fondo de la cuestión, el hecho es que el obispo de Puebla escribe con la ventaja inicial del realismo.

La tercera es el atractivo de una narración no sólo entretenida, sino fascinante. En primer lugar por la descripción de las experiencias de la

diziendo que había ido al purgatorio y que vido muchas ánimas que estaban penando y que truxo en los pies el fuego del purgatorio y dezia a las gentes que penaba ella por las ánimas que estaban en el purgatorio...» (p. 59).

(5) PALAFOX Y MENDOZA, J. DE, "Luz a los vivos y escarmiento en los muertos. Ed. en Madrid en la Imprenta Villa Diego, $1668 ; 547$ pp. aunque el texto que aquí comentamos sólo ocupa hasta la p. 342; el resto son dos "apéndices" con doctrina pastoral. Lleva un prólogo en el que se comenta la personalidad y virtudes de la Vble. Madre Francisca del Santísimo Sacramento del Convento de S. José de Pamplona, supuesta vidente. La cita en la p. 1; como referencia a la vida y el papel político de Palafox puede ser útil: SÁNCHEZ CASTAÑER, F., D. Juan de Palafox, Virrey de Nueva España, Zaragoza 1964. (Reedic. Madrid. 1988).

(6) IBíDEM, p. 92. 
monja misma (pese a su brevedad y esquematismo reiterativo) y luego por el cúmulo de nuevos ejemplos y casos que el obispo añade en sus comentarios y que, de hecho, constituyen, prácticamente, otro libro dentro del libro. Piénsese que sólo en las primeras cincuenta páginas, aparecen treinta "casos» distintos, de este tipo, reforzando las 36 visiones que hasta ese momento se comentan; de otra parte, algunos de estos "exempla" adquieren vida propia y constituyen apólogos extensos que podrían recordarnos el recurso estilístico de una «novela dentro de la novela». Tal por ejemplo el del cura-ánima y el pastor de la villa de Enciso que se extiende desde la pág. 66 a la 85, o el de las ánimas de Veracruz, de 1654, que ocupa desde la pág. 136 a la 140 . El conjunto «a vista de pájaro» resulta un mosaico de casos de lo más variopinto, que recorren toda la escala desde el misterio-intriga al tremendismo; no se encontrarán mejores en ningún «almanaque». Algunos no desdeñaría firmarlos Italo Calvino (7); en otros, la narración es sustituida por la reproducción de las actas testificales de tribunales eclesiásticos que intervinieron en ellos (8) o por la de cartas en las que se comunicaron en su día (9). Con alguna imaginación su lectura resulta aún hoy sumamente entretenida, de modo que añadiéndole la confianza absoluta en su realismo, propia de la mentalidad del XVII, el efecto sobre el lector debía ser muy absorvente. Con todo, es verdad que la superabundancia de la oferta de situaciones medroso-maravillosas, terrorífico-excitantes o morboso-sugestivas, en la literatura religiosa de la época, debería haber estragado los paladares imaginativos, acolchando el impacto buscado; pero aun así el libro no sólo «se deja» leer, sino que "engancha».

Por último y para abreviar, los mensajes doctrino-morales no constituyen un corpus independiente más o menos organizado con la declamación emotiva (como es el caso de los "Gritos" de Boneta, en los que entre cada "grito" se intercalan capítulos estrictamente doctrinales como "de la pena de sentido que padecen las almas en el purgatorio" o "de las culpas que llevan al Purgatorio y de los medios penales con que se pueden satisfacer»), sino una baraja de reflexiones y sugerencias en los que no falta el lenguaje popular y el practicismo inmediato de aplicación doctrinal a situaciones concretas y perfectamente adecuadas a la vida coti-

(7) IBÍDEM, p. 30. «Pasando muy cerca de Roma un hombre devotísimo de las ánimas... encontró colgado de un árbol un hombre hecho quartos a quien él encomendo mucho a Dios. Al punto los quartos divididos se juntaron y baxó del árbol y le dixo que se apease del cavallo que le iba la vida en ello...".

(8) IBÍDEM, pp. 67 y 55.

(9) IBÍDEM, pp. 137 y 55. 
diana (10). Al tirar de la cereza del "cuento» se viene detrás el racimo de los modelos morales de conducta.

Pero ya es larga presentación del libro, y hora de bucear más apretado en sus contenidos.

\section{Alguna ESTAdística Y NO POCAS NUECES}

El libro está montado sobre 229 «relaciones» redactadas por una religiosa de la que se nos dan noticias en el prólogo, de forma que, sabemos que es de familia noble. La primera y la última son explicativas de por qué las escribe y por qué las dejó de escribir, de modó que quedan 227 "relaciones» de apariciones. De ellas, en realidad sólo corresponden a almas del purgatorio 214: (lo que no parece un mal récord para una sola monja) siendo las otras 13 , "visiones" beatíficas, consoladoras las menos (sólo tres) y luchas físicas con el demonio o visiones «infernales» la mayoría (diez). Así púes, disponemos de un "universo" social de $214 \mathrm{ca}-$ sos para la radiografía socio-moral que intentamos. Una de las peculiaridades de semejante "universo" social es la trabazón "familiar» (no ex-

(10) Así, «.... el decir que le dio un desmayo no desacredita la aparición, porque muy ordinario es temer el alma cuando se le aparece Angel o otro espíritu de superior orden..."; "... también es de notar que se aparecían en el habito de su Religión, conservando en el Purgatorio lo que en esta vida les había salvado...n; o también "... y que de lo que tocaba al voto de pobréza se tomaba estrechisima cuenta allá: y de cosas que aquí no se hacía caso. Y que padecía mucho por unos escritorios de nogal que tenía en su celda..."; "..., el hombre cuya alma se le apareció fue un mozo que mataron unos soldados de un caravinazo... y le mataron al anochecer defendiendo el que unos cavallos de los soldados, que estaban alojados en el lugar, no se comiesen los trigos que estavan en las heras..."; cn ocasiones no elude el chiste, sin que deje éste de contener un mensaje doctrinal, como cuando refiriéndose al Demonio que tienta a un pastor prometiéndole enseñarle a saltar y tirar la barra (enternecedor precursor bucólico de un Mefistófeles de aldea) subraya: «... lo cierto es' que él (el Demonio) puede enseñar a saltar porque él dió el mayor salto que se dárá jamás, desde el cielo hasta el infierno". La selección de citas podría ser interminable: ".... claro está que este buen sacerdote no avria sido usurero... sino que iria ahorrando algunos realejos y se holgaria de que creciese la bolsa»; "... Es perdida la mujer por galas y devaneos ... quema su casa y aún su honor con sus vizarrias y luego dicen, es bonisima señora sino que tiene aquella condición esparcida»; "... con las mismas veras se toma residencia de la cebada que se quitó a un pesebre y se mudo a otro que del Reyno que se usurpo...." "... si el viñadero se come las ubas; si el pastor se come las ovéjas; si el alguacil se buelve ladron, quien guardara la viña, el ganado o las haciendas?». Baste pues este no escaso botón para tan nutrida mercería. 
clusivamente por parentesco, aunque también) de la muestra. No sólo aparecen las ánimas del tío, el sobrino o el criado de los padres de la religiosa, sino compañeras de claustro, superioras antiguas o recientes del convento y oficios directamente relacionados con él, como proveedores (en el caso de una hornera y una cerera); además, su confesor, otros parientes y oficios del entorno inmediato, como el herrero o los mesoneros. Es precisamente este reducido y «familiar» conjunto una de las razones que avalan la existencia del cuaderno monjil; si Palafox hubiera "elegido" las apariciones, a buen seguro los protagonistas habrían estado más dispersos por el abanico social o habrían sido escogidos de otra forma. El "mundo" de los aparecidos refleja mejor el de una monja de clausura de buena familia que el de un obispo culto que pretende un «libro de estados". Vamos a precisar más. La primera advertencia es que no se trata de 214 ánimas diferentes; las repeticiones son tan frecuentes que muchas de estas ánimas aparecen diez veces y más. Prescindiendo de este detalle, 157 corresponden a hombres y 57 a mujeres; la proporción parece un poco alta si pensabamos utilizarla como simbólica del peso respectivo de ambos sexos en la sociedad real; pero si advertimos que 31 de esas mujeres son monjas, nos quedaría una relación mucho más significativa. Curiosamente, el esquema estamental del conjunto es absolutamente equitativo: el $36,4 \%$ de los aparecidos corresponden al CLERO (78 apariciones en total), el 30,8\% a la NOBLEZA (66 apariciones) y el 32,7\% al ESTADO LLANO (70 casos). El clero regular se lleva la parte del león (como era de esperar, según el estatus de la visionaria) con 49 casos (31 femeninos y 18 masculinos) frente a los 29 del clero secular. En la nobleza el predominio masculino es completo (62, contra 4 mujeres y aun alguna de ellas dudosa) y en el estado llano simplemente doble, 48 hombres y 22 mujeres. Curiosamente, en alguno de los subgrupos de este conjunto la proporción femenina es mayoritaria: el mundo del trabajo (artesano-oficios) cuenta con 12 mujeres frente a 4 hombres, y el de aquellos que no tienen más señas que la generalización (viejos, mozos, doncellas, casados, viudas,...) con 10, frente a 9 hombres. En resumen, un "mundo" hipertrofiado en la representación de las élites dirigentes (el clero y la nobleza acaparan el 67\% de los aparecidos) y cuyo sesgo supermasculino (el $73 \%$ de las apariciones lo son) queda matizado sugestivamente por la superioridad de las religiosas en el clero regular, y de las mujeres entre los distintos "oficios". Este matiz último debe, a su vez, ser explicado, me parece, por dos motivos: en primer lugar por la distorsión que supone la repetición masiva de un solo personaje (una mesonera); en segundo, en cambio, por la "evidente" falta de información sobre el mundo del trabajo que una religiosa de clausura, noble, manifiesta. También es probable que la cifra de nobles pu- 
diera ser algo superior si tenemos en cuenta que no se han incluido en ella «los Oydores» que, con las consiguientes repeticiones, aparecen hasta 12 veces. Como puede apreciarse, el obispo no dispuso de una estratigrafía social demasiado rigurosa, de modo que debió sacar partido a la reducción "inocente» que la religiosa le proporciona. Aun así, el panorama sociológico no deja de resultar revelador, sobre todo si lo comparamos con los "Gritos" de Boneta. Veamos; atendiendo a "prototipos" sociales, la monja proporciona aparecidos de los siguientes: ARZOBISPO, OBISPO, CANÓNIGO, PREBENDADO, SACERDOTE; SUPERIOR (A), RELIGIOSO (A), DONADA; un muestrario clerical muy completo; CABALLEROS, DAMAS, una nobleza esquemática; OYDORES-JUECES, MINISTROREGENTE, VIRREY (sospecho que en la acepción genérica de alto funcionario, simplemente) ESCRIBANOS (DE CÁMARA también) ALCALDE, CAPITÁN, una cúpula de poder administrativo, judicial y militar, más bien tópico-genérica salvo en lo que a los jueces se refiere; ESCUDERO, MESONERO, HERRERO, SOLDADOS, CERERA, HORNERA, un mundo del trabajo un tanto peculiar, y MERCADERES, MÉDICO y BOTICARIO, LICENCIADO-LETRADOS, unas "clases medias" harto esquemáticas. Luego, existen algunas denominaciones genéricas como CASADA, DONCELLA, MOZO, VIEJO, HIJO, SEGLAR, que no aportan nada específico.

Teniendo en cuenta que con frecuencia los mismos personajes aparecen muchas veces, como luego veremos, la distribución de frecuencias aparece en el siguiente cuadro que recoge el total de veces que cada prototipo aparece, sea o no repetido el personaje:




Si de semejante conjunto tuviésemos que obtener la visión del mundo de la monja (lo que me parece posible) no tendríamos dificultad en diseñar un "universo" partido en dos bloques sensiblemente iguales: clero y nobleza; cada bloque ha proporcionado 78 aparecidos (incluyendo los oydores); este es su universo real, el resto es un inexpresivo conjunto de "salpicaduras" cuya existencia parece reducida a su experiencia inmediata. Los nueve mesoneros son en realidad una y uno; el escudero es el criado de sus padres; la cerera es proveedora del convento, el capitán es un familiar; uno de los soldados es un "guarda de puertas" que puede haberle llamado la atención en algún viaje; el herrero es oficio relacionado con carruajes y pudo tener contacto directo; médico y boticario son oficios con ejercicio en el convento... etc. Sin duda Palafox habría distribuido de otra formma "los estados», pero es lo que tenía e incluso se le daban ya hechos los pecados que purgaban; sacar partido de ello es lo que determina su esfuerzo e ingenio pastoral. Pasemos pues a esta segunda visión del mundo: las disfunciones que se perciban proporcionarán "en negativo" el paradigma que se propone. Puesto que el «juego" consiste en buscar la peculiaridad de los fallos del sistema, seguiremos el esquema de los pecados-sociales, tal como los van declarando los aparecidos.

\subsection{El clero: poco sexo y algunas sorpresas}

Naturalmente no es fácil obtener una homogeneización entre el regular y el secular; será mejor, pues, examinarlos juntos, pero no revueltos. En el clero secular se citan diez pecados distintos (luego cada uno puede aparecer repetido), a saber: "pretensiones" y demasiada solicitud en alcanzar dignidades; pleitos parroquiales en beneficio de la propia honra; ambición y pleitos familiares por interés; frivolidad de vida secularizada y "mocedades» (es decir sensualidad); descuidos en la dignidad sacerdotal $\left({ }^{\star}\right)$ y falta de reverencia en las prácticas religiosas; falta de ejercicio pastoral y desatención a las necesidades de sacramentos de los feligreses; falta de capacidad de gobierno e incumplimiento de los deberes graves de mando; nepotismo en la administración de las rentas episcopales; juego y liviandades; ansia de valer y ser estimado; falta de previsión al ordenar aspectos de utilidad espiritual.

Como puede apreciarse, la "vida desordenada" parece ocupar poco lugar respecto a lo que llamaríamos "pecados profesionales». Una sola vez se cita el haber tenido una hija, y aun entonces Palafox sale al paso

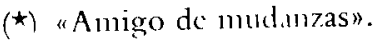


señalando «...pagará los delitos de juventud si ya la hija que tuvo no fue aviendo sido casado antes de sacerdote...".

Dada la sencillez del enunciado en las relaciones de la monja, es preciso jugar a la vez con la extensión e intensidad de los comentarios de Palafox. De este modo el "modelo" de mundo desordenado de la religiosa se podría modificar-intensificar con el juicio del obispo. En efecto, Palafox es muy claro respecto a la gravedad relativa de los pecados e insiste en la mayor gravedad de los que afectan a la función: “... y procuremos no pecar en los oficios que es el medio único de escapar de las acervas penas del purgatorio.... y en otro lugar «... jo, que dellos se condenan porque confessandose de las culpas de la persona se olvidan de las del oficio!..." "...en su casa pagava los pecados de la persona y en el calaboço los del oficio (era un juez) porque se pagan siempre más duramente estos que aquellos». "... entre ambos fueron defecto del oficio y yo estoy rezelando que estos se pagan con mayor severidad que los de la persona... pues el que peca en la persona no pierde más que a uno pero quien peca en el oficio a muchos" (11).

El verdadero hincapié se realiza sobre tres pilares de desorden: la incapacidad de gobierno y su disfunción, la ambición y el descuido pastoral; como fallos complementarios, la codicia y, de pasada, la liviandad (12). En realidad, a algunos de estos fallos (los de administración epis-

(11) PALAFOX, op. cit., las citas respectivas en las pp. 85, 48, 24, 13.

(12) Puede comprobarse la distinta intensidad con que se aprecia la disfunción, en la redacción misma del obispo: Para la incapacidad de los prelados en "su oficio" tiene palabras como las siguientes: "... con mitra pecó, con mitra padezca...», "... llena obispo tu ministerio, advertido... que no basta que obres mucho de lo que puedes si no obras todo lo que puedes y debes...", "... antes dixo las culpas de omission que las de comissión; porque en los obispos son mayores aquellas que no estas...», "... No predicar, no exortar, no governar, no velar... no zelar, no corregir... si nada de esto hace ¿donde está el obispo?». (p. 160) e incluso le sirve de pretexto para enzarzarse en una disputa canónica sobre la utilización de las rentas diocèsanas "... que no puede el obispo dar sino para la diócesis... que no se puede gastar sino en la diócesis... no se puede dar sino en los pobres de la diócesis" (162) y esto lo considera "Teología del purgatorio... más segura que otras que por aca corren...". Para la ambición hay también doctrina terminante no exenta de ironía feroz: "que el que no merece ser sacerdote quiera ser prebendado y el que no vale para canónigo aspire para obispo... esto es lo que allá se paga» (p. 100) «que debiendo pretenderse con medios de virtud se procure el premio con exquisitos favores o otros modos interesados e ilicitos... esto son demasiados pretenciosos" (101). La falta de atención pastoral y la secularización del estilo de vida le llevan a comentarios más sarcásticos que de indignación: “... debía ser un clérigo alentado de los que sobresalen en vizarria... la mejor espada y la mejor guit.ırra del lugar. Todo esto cuesta 
copal) había dedicado el propio Palafox una obra específica: la Trompeta de Ezequiel (1658) y una de sus obsesiones es la falta de gobierno, que condena con reiteración: «Es gran prelado dicen tal vez del obispo, sino que tiene aquella condición de no querer hacer mal a nadie y de no saber negar cuanto le piden, con que no hay justicia... y todos viven en el obispado... sin memoria alguna de gobierno...» (13).

Respecto al clero regular se repiten: la ambición, la lascivia y la codicia; pero las claves vuelven a aparecer en los "pecados de oficio" con alguna presencia llamativa. En efecto podemos volver a distinguir los desórdenes funcionales: gobernar con pasión y persecución a otros hermanos; excesos en las reformas internas; opresión sobre los novicios para profesar; esto, por lo que atañe a los superiores. Enfrentamientos con sus superiores, exceso de amor propio y falta de constancia en la religión, por lo que se refiere a los simples religiosos. Un capítulo muy extenso a la vanidad del predicador y el desagradecimiento a los favores divinos, podíamos considerarlos como complementarios. No olvidemos que las relaciones de la monja proporcionan sólo los puntos geométricos; el diseño y la intensidad del dibujo lo aporta Palafox (14). En rea-

tormentos intolerables...", "... Puede ser que no estuviera en el purgatorio este Sacerdote si como embiava a los hombres a morir en los hospitales su valentía, fuera a curarlos y servirlos su caridad...”. La codicia le sugiere una no muy común doctrina: "... porque el que grangea y hace de su dinero tesoro a nadie aprovecha, ni a si ni a los otros porque no lo comunica, pero el que grangea primero y lo derrama después es canal por donde corren las riquezas y ya por lo menos causa utilidad a algunos"; anotar la evidente contaminación "capitalista" del juicio moral convertido en axioma cuasi keynesiano. La liviandad no merece más que comentarios tópicos en los que Palafox no se muestra muy interesado: «... pecados de mozo, edad verde, deleites verdes, culpas que entran muy verdes en el purgatorio..." o bien "... estas «mocedades" que tienen tan sencillo el nombre encubren y cubren sapos, culebras y basiliscos dentro de sí..." (35).

(13) PALAFOX, op. cit., p. 54.

(14) La "elección" de los desórdenes del clero regular masculino se aparta bastante del tópico del fraile comilón, desvergonzado y vago, como puede apreciarse; es decir, que tales lacras no son las que preocupan ni a la religiosa $n i$ al obispo. Sobre el "gobernar con pasión" advierte Palafox: "... pudo governarlo el zelo en la persecución, aunque destemplada y pagava la destemplanza... al segundo la pasión sin el zelo le governo y assi estuvo cerca de condenarse... el aviso que goviernen sin passión es discreto y espiritual y deve estimarse más por ser de escarmentados...", "... muchas veces se le arrima esta (la passión) al zelo y le haze que se desvie de la caridad que ha de ser el alma de los preceptos". Sobre el exceso reformista señala: «... el alterar la Religión para reformarla... puede ser que a esto arrimase alguna pasioncita y sobrado amor imperfecto a sus propios dictámenes...". No hay vio- 
lidad el énfasis lo pondrá el obispo en la obediencia, la dignidad y la superioridad del estado religioso y no en la crítica de los excesos de autoridad. Yo me atrevería a sugerir que, en este diseño, la "visión" de la monja y la del obispo no coinciden.

Los desórdenes del mundo religioso femenino, como podía esperarse, (teniendo en cuenta la fuente) constituyen un "recinto" diminuto de pequeñas miserias sin mayor trascendencia; un mundo habitado por la vidente y que se manifiesta como el retrato subconsciente de su vida cotidiana y su escala de valores. Le sirve a Palafox para insistir en la perfección de la vida religiosa y poco más. A pesar de ello no dejaré de enumerarlos porque constituyen una fotografia realista (aunque edulcorada) del mundo conventual. Vuelve a aparecer el hermetismo culpable ante la Superiora; la afición desordenada a la posesión de objetos en las celdas (aun con permiso); la falta de concentración en el oficio religioso; el nepotismo y algún desorden en la administración económica de superioras; los juicios de valor sobre otras hermanas; apego a los bienes de la anterior vida mundana; debilidad en guardar y hacer guardar la regla; faltas de puntualidad o de humanidad, etc. Tres desórdenes a destacar (al menos en función de la atención que les presta Palafox): los afectos ambiguos, los excesos de los sentidos "decentes» (aromas y buen paladar) y la frivolidad, con sus excesos de locutorio y otros entretenimientos.

A destacar, con todo, que la afectividad desviada la entiende Palafox (no sé, la monja) como un problema de convivencia, al crearse ca-

lencia en la crítica ni al perseguidor ni al reformador. Respecto a la presión sobre los novicios se limita a señalar que fueron "defectos del oficio». Mucho más contundente se muestra con el predicador pagado de sí mismo: «devia ser muy pulido predicador, los que llaman brillantes. Devía andar enamorado de si y quería predicar mucho porque lo alabasen mucho y. que saliessen de la Iglesia diciendo: $O$ que gran predicador!, Bravo orador!, Grande ingenio! Florido estilo!...", "... niega a Dios los aplausos que, sobervios, quieren atribuirse a sí mismos... si este predicador acostumbrasse antes de predicar a tomar una disciplina, ayunar asperamente, tener gran rato de oración y otras mortificaciones... no deseara sermones que cada uno le avia de costar estas resquebrajaduras». «... El buen subdito assi ha de presentar su coraçon descubierto a su prelado como lo tiene manifiesto a Dios.... no solo no debe engañar; pero ni dissimular cosa alguna a la noticia de los Superiores». "... de primo ad ultimun se reduze a falta de respeto y veneración a los Prelados y Superiores la ruina de la Regla... todos juntos no sabemos nada pues no sabemos obedecer"; "... se dexan de obedecer (las normas)... por pensar que saben más los religiosos que los priores y los Priores más que los Provinciales y los Provinciales más que el General; los feligreses más que los Curas; los Curas más que sus Obispos y los Obispos más que el Papa». 
marillas y favorecerse celos y reacciones contra el buen gobierno del convento.

\subsection{Los caballeros; pleitos, deudas, juego y alguna moza}

Ya he advertido que la religiosa es noble; de este modo el estamento aparece "domesticado» y con un tono de tíos y sobrinos que puede trivializar el mundo resultante. No obstante, Palafox parece cómodo con los apuntes de que dispone y de acuerdo con la grave disfuncionalidad de los tres pecados que parece reconocer como los paradigmáticos del "oficio" nobiliar. Los pleitos (justos, injustos, familiares, institucionales, por intereses, por vanidad, por honra) se erigen como el desorden estamental por excelencia. Proporciona ello un perfil que no desdice incluso de estudios actuales. Ya había topado el obispo con almas clericales aficionadas en demasía a pleitear, pero los había despachado (como cosa menor) con admoniciones sobre la conveniencia de no salirse de la jurisdicción eclesiástica y evitar enfrentamientos entre el clero secular y regular (15). Ahora lo enfrenta como combate estrella y abuso de alto bordo: "...este Cavallero tuvo dos purgatorios... el uno pleiteando y el otro purgando: el uno para ganar el pleyto y el otro para satisfacer a la culpa de seguir aquel pleyto. Finalmente el uno al comerlo y el otro al bomitarlo". $O$ bien: "Dixo que padecia por aver defendido pleytos injustos con su hermano. Dos injusticias, ser con su hermano y que fuesse injusto"; o este otro: "él como poderoso en ellos (unos lugares en disputa de vasallaje) hiziesse exquisitas diligencias... no por ellos (los lugareños) sino por él y su vanidad y que los hubiese violentado... de que hubiesen resultado gastos, costos pleytos, pecados y perjuizios... el tanteo de los lugares lo pagaba con el de sus penas en el purgatorion; $o$, finalmente, este último ejemplo: “... la segunda causa porque padecía era porque deseava inmoderadamente salir con los pleytos sin reparar en el perjuizio ageno y por punto de honra... con esto manifiesta que quantos pleytos fueren torcidos en el principio, en el medio o en el fin, aunque se vençan en esta vida, se han de pagar en la otra» (16). Las deu-

(15) PALAFOX, op. cit., «... en este caso tenia más culpa el capellan (del convento) porque siendo pleyto de convento con parroquia, que es totalmente eclesiástico, avia de seguirlo ecclesiásticamente (lo que al parecer el ánima en pena no había hecho)... y así es menester no solo tener razón en la causa sino guardar buena forma en la prosecución....".

(16) PALAFOX, op. cit., pp. 38 a 115. Pero podríamos seguir acumulando citas como esta otra: «Raras veces grandes pleitos se sustentan sin grandes imperfecciones, aunque se vença en ellos y se tenga razón, porque porfiar mucho y no pecar algo no 
das y el juego (sobre todo las primeras) acompañan. Es verdad que respecto a ellas no se muestra el prelado tan puntilloso como con los pleitos; incluso, en los primeros casos, concede al término «deudas» un significado metafórico, como deudas espirituales. Pero la avalancha de apariciones que penan por deudas le "obliga» a tomar en serio el tema, y así desde su primer comentario, "Por deudas padecia, no serían solo de dinero sino de culpas... pues si él solo huviera contraido deudas... no las pagara allá aunque las deviera acá», desemboca en otros más realistas como: «... la proposición de esta alma que no saldría del purgatorio hasta que se pagassen las deudas es muy conforme a la doctrina... pagemos aquí con lágrimas mientras no podemos con dineros: y en pudiendo, sin ninguna tardanza, paguemos con ellos para no pagarlo allá con tan crudos tormentos" (17). De todos modos el tema debía ser espinoso porque obliga al buen obispo a recurrir a una elegante maniobra retórica para matizar: "Pero también se advierte que aquí reprehende el Señor a los que se empeñan por vanidad y no pagan; pero no a los que se empeñan por caridad y por necesidad... que esto lo han hecho grandes santos» (18). El juego y las mozas se examinan mucho más levemente. Con todo, puede resultar sugerente subrayar que es contra el juego femenino donde Palafox alinea sus baterías con más intención (19). No merece la pena entrar en las Damas nobles, sobre las que cae poco más que la vanidad de los afeites, el juego y la maledicencia; aquí la personalidad de la vidente resulta, una vez más, neutralizadora.

es muy facil de conseguir» (p. 123) o también: «... tuvo un pleito matrimonial que hizo mucho ruido... comenzo con peligrosos empeños, devió de proseguir con desempeños y derramamiento de gasto de hazienda... corrió por muchos tribunales... costó gran golpe de hazienda, discordias, desabrimientos... el suceso fue gastarse entrambos, vencer la una y pagar rigurosamente en el purgatorio" (p. 122).

(17) PALAFOX, op. cit., pp. 16-17.

(18) PALAFOX, op. cit., p. 18. Como matiz interesante obsérvese este corolario al gasto excesivo, aplicado al "hambre" de títulos nobiliarios "... padecia por la pressunción y por la pretensión de ser título y por la hacienda que en esto gastó... se repara (en la otra vida) si se gasta en la vanidad lo que se deve al recto y justo uso de su hazienda... luego ¿no podre yo comprar cavallos, coches, literas y quanto quissiere?... quanto hiziere por antojo y sin medida, leve o grave, lo pagará en la otra vida..." (p. 132).

(19) PALAFOX, op. cit., pp. 28-29: "... es muy conveniente que purifique el fuego el tiempo que se perdió en el juego" «... porque o se pierde el dinero o el tiempo con excesso... y más en las mujeres que si comienzan a jugar a los naipes suelen jugar la honra con el tiempo y el dinero. Sólo jugar el tiempo, una mujer que tanto le ha menester para el govierno de su casa es perder una moneda de gran precio, quanto más que si juegan con hombres allá puede ir todo». 


\subsection{Los jueces y escribanos: un arsenal de doctrina}

El racimo de Oidores que pasean sus quejas y solicitudes por las relaciones de la monja, proporciona a Palafox la posibilidad de entrar en una reflexión sobre la justicia, el gobierno, el desorden, la misericordia y la responsabilidad. Unos pocos escribanos, al parecer convictos de ambiciones, fullerías y abuso de oficio, le permiten enfrentar con inesperada extensión el problema, nada común, de la licitud de la venta de oficios y sus consecuencias sociales. No son temas baladíes ni de los más generales (sobre todo el segundo) en la literatura devocional. Verdad es, sin embargo, que ambos se prestan a recurrir a una retórica tópica muy generalizada, por encima de la vida cotidiana de la gente común. Veamos como aborda nuestro obispo estas materias. El tópico pedagógico del juez juzgado (tan barroco, por otra parte) sirve de pórtico a la materia doctrinal sin que rehuya el juego de palabras: "Este Oydor merece ser oido. De juez, juzgado y de Magistrado reo. Ya dava memoriales el que los recibia y rogava el que le suplicavan". Comienza después con aquellos desórdenes de mayor impacto popular: «...como consejero (el Oidor en pena) aconsejó desde el purgatorio a los Oydores de su Tribunal... tres cosas utilísimas: la primera que abreviassen las causas; porque purgatorio si no infierno es el que padecen los pobres litigantes, cuando no los despachan, haziendoles gastar el tiempo, el dinero y la vida y tal vez la conciencia... la segunda que juzguen sin respetos humanos y en esto no miro ya a... la brevedad sino a la sustancia de la verdad y justificación de la sentencia... la tercera que juzgasen en el tribunal a vista del Purgatorio... porque ay ministros superiores de la Divína justicia que castigan duramente a los de la humana». Paso por alto los no despreciables contenidos de consolación sicológica que contiene todo este desarrollo de jueces-reos, e incluso la sugestiva hipótesis (expresada por la propia ánima en pena) de que el purgatorio de un juez se purgaba en un calabozo (20). Tales reflexiones no son sino el prólogo de la «teoría general de la justicia y el gobierno", uno de los pocos desarrollos con carga netamente política de todo el libro. Algunos tópicos de la retórica clásica no excluyen la defensa a ultranza del orden y la disciplina: «... el juez deve en todo mostrar su humanidad... que antes firme la con-

(20) El obispo se recrea en esta situación barroca: "Quien le dijera a el... que avia de penar en el calabozo adonde embiava los presos?... verosimil es que fuesse destemplado en el zelo y que pagase justamente lo que devia en donde injustamente avia hecho que otros pagassen lo que no devian... O quantas veces, sin que lo sepan los presos estan penando con ellos las almas de los juezes!..." (op. cit.), pp. 24-25. 
denación con lágrimas que con tinta... no ha de morir nadie de su mano sino aquel que, porque no pueda ya ser util ni para si mismo su vida, aproveche a la República con su muerte». Poco a poco va explicitándose la tesis: «El buen ministro... del Rey... ha de llegar con la clemencia hasta no tocar en la relajación... Perdonarlo todo es crueldad igual $y$ aún mayor que castigarlo todo; porque más daños causa en la República la misericordia sin justicia que la justicia sin misericordia" (21). Que la cita corresponda a Séneca y que se la "mejore» no debería producirnos ninguna extrañeza (22).

Pero tal vez sea en la reflexión sobre la compra de oficios, que le sugieren las penas de un escribano de Cámara, donde se desarrolle una doctrina menos familiar para el lector de libros piadosos: «El alma del que compró el oficio repetia... por sufragios, deshaziendo con esso los passos que dió a la ganancia, que en esta vida fue de dineros y en la otra de penas".

No es más que el zaguán del asunto; pronto entra en la sustancia: "comprar con honesto fin un oficio vendible no trae consigo culpa alguna... por lo que toca a los que lo compran con buen fin parece que está justificada esta opinión, como no lo está para los que lo compran para hacerse ricos...»; el problema radica en explicitar qué es el «buen fin". Hay pues que recurrir a la doctrina y matizar que hay oficios y oficios: «En quanto a la venta de los oficios, que no son de justicia, parece que está assentado que no se peca al venderlos: con lo qual... menos se pecará al comprarlos", pero los oficios que corresponden a funciones "de justicia», «... apenas puede llegar caso en que sea licita la venta". En su opinión, en todo caso, el tema afectaría más bien a Francia que a España, cuyo rey "como tan zelozo de la justicia» "nunca ha permitido que se platique (practique) este medio en sus Reynos»; pero al parecer es mejor opinión mantenerse alejado de tales compraventas, "porque no es muy fácil en materia de interes y en oficio comprado, contenerse en lo moderado, sin tocar en lo excessivo" (23).

(21) PALAFOX, op. cit., p. 44. El razonamiento se justifica en el párrafo siguiente: «La razón es llana porque la justicia sin misericordia exercita sus efectos y reforma y contiene y enfrena y mejora aunque con algún rigor; pero la misericordia sin justicia relaja, destruye, abrasa y quema la República, dexando libres los delincuentes, los quales persiguen y oprimen a los inocentes".

(22) Aprovechando un ejemplo distinto Palafox insiste en variaciones sobre el tema: "Dudan algunos políticos qual es peor, el govierno vario o el tirano y assientan que es peor el vario (es decir, el indeciso, caprichoso y sometido a mudanza) porque el tirano ya es govierno pero el vario no dexa govierno sino confussión" (p. 88).

(23) PALAFOX, op. cit., citas en las pp. 84 y 102-103. 


\subsection{La gente común: trapacerías y mezquindades}

Ya advertimos cómo este conjunto se difuminaba en trazos desvaídos (acordes con la "experiencia» de la protagonista religiosa) en torno a la vida conventual. El refrendo aparece en las culpas aducidas, que Palafox utiliza con habilidad. No es posible obtener más que la sensación tópica de debilidades picarescas con algún ribete cuasi literario (no necesariamente «falso»). La lista no será muy extensa y tampoco el comentario: alquilar bestias abusivamente y robar cebada de los pesebres (el mesonero); deshonestidades soldadescas y haber renegado, cautivo de los moros (los soldados); codicia y trapacería interesada (la hornera); enemistades vengativas y descuido con los enfermos (el médico); fraude en la mercancía servida al convento (la cerera); juego y ociosidad (el herrero); falso testimonio y chismorrería (la mesonera). Especial interés tenía el resultado que apareciese de la simbólica presencia de los dos mercaderes uno viejo y otro joven. Las culpas son tan genéricas y vagas que avalan la sensación de que este último "tipo" social no constituye, en opinión de monja y obispo, un pilar social que "exija" mayores precisiones en la conducta. El hecho de que ambos sean padre e hijo refuerza el carácter minoritario y anecdótico de los ejemplos. El viejo mercader padece "por sensual y codicioso»; tal situación no merece al obispo más que un breve comentario (casi divertido) sobre la contradicción entre ambos términos: «El codicioso suele ser casto por no gastar en el vicio... pero sensual como si fuese pródigo y codicioso como si no fuera sensual, es tomar lo peor de todo". Este juicio «moral», de base capitalista, es más sugestivo que el propio "capitalismo" del mercader, y así la conclusión apodíctica del obispo parece relacionada con un tratado de contabilidad: "y así menos malos son los vicios que, por lo menos, tienen alguna cosa de bueno o útil en lo malo". Por contraste el hijo resulta un "pródigo" (contraste bastante sencillo y al alcance de cualquier religiosa) que facilita inmediatamente el recurso al hijo pródigo por excelencia; el hecho de haber muerto ahogado le resulta más interesante a Palafox que su tipología de mercader, porque le permite una reflexión sobre las muertes repentinas.

Esto es todo lo que da de sí la radiografía social perceptible en un libro inicialmente muy alejado de semejantes menesteres. Naturalmente, hay otras cosas que podrían resultar socialmente, incluso más interesantes: me refiero a los mensajes complementarios en direcciones muy específicas. En un libro tan extenso tales mensajes son demasiado numerosos para tener aquí cabida. Baste por ahora con señalar que, aprovechando el motivo central, se organizan en torno al peso de la previsión eclesiástico-espiritual de las necesarias gracias postmortem; a la va- 
loración social del clero en sus distintas manifestaciones y a reforzar el sistema de creencias en la permeabilidad de la naturaleza ante la misteriosa existencia del más allá sobrenatural. Me ocuparé de tales extremos en otro lugar.

Quiero recordar, como colofón, la tesis inicial: el libro de devoción, que inevitablemente debe contener los elementos de atractiva diversión sin los que difícilmente conseguiría sus fines, tiene otras lecturas (ni siquiera excesivamente sesgadas) en la doble dirección de dibujar una radiografía social consoladora-igualitaria y proponer unos modelos de conducta que pueden oscilar entre la perfección y la simple «urbanidad» espiritual. 